\title{
A Personal Biography of Marty Weitzman
}

\section{Christian Gollier ${ }^{1}$}

Accepted: 26 September 2019 / Published online: 14 October 2019

(c) Springer Nature B.V. 2019

Marty Weitzman passed away on August 27, 2019. His contributions to economic theory and environmental policies have not been exaggerated by the many colleagues who have publicly expressed their deep sadness related to this unexpected loss. As for many other colleagues around the world, Marty had a deep influence on my research agenda and on the way I use to think and talk about several crucial policy issues of climate change. In their names, and in the name of the European Association of Environmental and Resource Economists, I express our collective gratitude to his leadership among environmental economists.

I would like to use this opportunity offered by the editor of Environment and Resource Economics to provide my own take-home messages from my interactions with Marty and his work. I first heard about Marty's work when I was a PhD student in the late 80s. Because I was trained as a macro/labour economists, I was not really aware of his already famous paper on "price versus quantity". At that time, Marty made the buzz worldwide in our profession by publishing his book on the "share economy" (Weitzman 1986). The big macroeconomic policy issue of the time was about fighting massive unemployment, not climate change. In a clear demonstration of his independent and creative mind, Marty claimed that one should change the nature of the remuneration system to massively reduce unemployment. In particular, labour contracts should stipulate a two-part tariff, with a minimum wage combined with a share of the corporate profit. Because the profit-maximization condition is to equalize the marginal productivity of labour to the fixed part of the remuneration scheme, a partial equilibrium analysis demonstrate the possibility of solving the mass unemployment problem. This was a huge thing, and all big names, such as Larry Summers, Bill Nordhaus and James Tobin, were involved in a tremendous debate about Marty's revolutionary policy recommendation. I would like to stress here how this debate is a perfect illustration of Marty's style: First, select a crucially important policy issue from scratch, and explore it without any a priori but with a clear mind. Second, write a very innovative proposal, test the reactions and withstand the opposite winds. Third, conclude and switch to the next challenge. Marty was indeed not only a great mind of our time, but also a lone fighter in the intellectual domain. His 10 most cited papers of his career are all single-authored.

I have at least three other issues that perfectly fit this framework: prices versus quantities, discounting, and the dismal theorem.

Christian Gollier

christian.gollier@tse-fr.eu

1 Toulouse School of Economics, University of Toulouse-1, Toulouse, France 


\section{Prices Versus Quantities}

All environmental economists know Marty's classical paper (Weitzman 1974) on the relative merits of the two standard methods to give a price on an environmental externality. This elegant paper is taught in all introductory courses of the discipline around the world. Almost five decades after its appearance, this paper is still playing a crucial role in shaping the debate about whether a carbon tax is better than a market for emission permits when costs and benefits are uncertain. The main message of the paper is that the market/quantity approach should be preferred when the marginal damage function is very steep at some concentration threshold. By fixing a quota of emissions below the threshold guarantees that it will never be crossed. On the contrary, the tax/price approach should be preferred when the marginal abatement cost function is very steep at some abatement target level. By fixing a tax on carbon guarantees that abatement costs will remain under control in all states of nature.

Marty was perfectly right to analyze that the uncertainty surrounding the damage and abatement functions is the crucial ingredient that needs to be examined before shaping an optimal policy. The remaining difficulty today is that the sources of uncertainty are extremely difficult to quantify. For example, we are still unable to quantify the positive and negative feedback loops in the dynamics of climate, and therefore the location of the potential catastrophic thresholds of concentration remains ambiguous. We also face deep uncertainties about the abatement costs to which we will be confronted in one and two decades. Moreover, it is crucially important for the actors of the energy transition to provide credible signals about the price of carbon that should prevail for these time horizons. Should we commit to high carbon prices in the future to promote the green R\&D and the early adoption of green technologies, with the risk of having to revise the price downward in case of an unexpected radical green innovation? Or should we commit on an emission target as those that have been promised in the "Nationally-Determined Contributions" of the Paris Agreement of 2015? Those hot questions today were already at the core of Marty's paper of 1974 !

\section{Discounting}

In the spring of 1995, Marty visited Toulouse for a month, invited by Jacques Crémer who had been his graduate student at MIT in the mid-70s. This was when I myself started to work on climate change and long-term discounting, expanding my earlier investments in decision theory. In an internal seminar attended by Marty, I used the following standard asset pricing formula to examine whether one should use lower discount rates for longer maturities:

$$
r_{t}=\delta-\frac{1}{t} \ln \left(E_{0}\left[\frac{u^{\prime}\left(C_{t}\right)}{u^{\prime}\left(C_{0}\right)}\right]\right) .
$$

In this equation, $r_{t}$ is the socially desirable discount rate that should be used at date 0 to discount a safe benefit maturing at date $t, C_{t}$ is consumption at date $t, \delta$ is the rate of impatience, and $u$ is the utility function of the representative consumer. This equation just tells us that the immediate utility loss today $\left(u^{\prime}\left(C_{0}\right)\right)$ should be equal to the discounted future utility gain of the safe investment with return $r_{t}$, which is equal to $e^{-\delta t} e^{r_{t} t} E u^{\prime}\left(C_{t}\right)$. Thus, the 
term structure of discount rates depends upon the shape of the utility function and upon the uncertainty surrounding consumption in the future. For example, under CRRA and no serial correlation in annual growth rates, the term structure should be completely flat: One should use the same rate to discount safe benefits occurring tomorrow or in 200 years! One week later after my presentation, Marty came to my office to tell me that he found my idea interesting but too complex. He then explained to me what would become the core of his famous two papers (Weitzman 1998, 2001) on gamma discounting. We all know the argument but let me restate it in a nutshell. Let $R_{t}$ denote the average short-term interest rate that will prevail between dates 0 and $t$. Seen from date 0 , this return is uncertain. Weitzman claims that in such an environment, a safe investment should be undertaken if and only if expected NPV is positive, when using the uncertain $R_{t}$ as discount rate. This yields the following "certainty equivalent discount rate":

$$
r_{t}^{W}=-\frac{1}{t} \ln \left(E e^{-R_{t} t}\right)
$$

As the story goes, if $R_{t}$ is stationary, the term structure of discount rates $r_{t}^{W}$ is decreasing with maturity and tends to the smallest possible future short-term interest rate for far distant horizons.

To quote Gollier and Weitzman (210), "the so-called "Weitzman-Gollier puzzle" is the fact that two seemingly symmetric and equally plausible ways of dealing with uncertain future discount rates appear to give diametrically opposed results with the opposite policy implications". The differences that prevail between the above two equations made our discussions quite difficult from the beginning. I was using the language of the asset pricing literature, and he was using the language of public economics. It basically took two decades for both of us to write the dictionary to interpret the other language with one's own words. In particular, Weitzman invested heavily in the asset pricing literature, which yielded another of his most famous paper, this one showing how that literature was sensitive to the non-tested assumptions about the fatness of the tails of the growth of $C_{t}$ (Weitzman 2007). More importantly, this allowed us to write our joint paper (Gollier and Weitzman 2010) that shows how our two pricing equations can be reconciled.

The most interesting point of this debate in which many researchers were involved is that Marty was right in his conclusion that one should use smaller rates to discount more distant safe benefits. But what was missing in his initial story was an economic intuition and an economically founded argument. I agree with him that parsimony is a quality in science, and that his gamma discounting model was the most parsimonious model I have every seen in y career. This made his argument very hard to resist. Great Britain (in 2003) and France (in 2005) were extremely fast to adopt their new decreasing discounting system in the aftermath of the publication Marty' gamma discounting papers. And here is now the intuition that Marty and I extracted from the controversy and that was embedded in our two models with our different languages. When growth rates of consumption are positively serially correlated, the uncertainty surrounding future consumption will accumulate faster than under independence, a condition that implies a flat term structure of discount rates. Because the uncertainty affecting future consumption is a precautionary argument to do more for the future, i.e., to value more investments, this positive serial correlation implies a decreasing term structure. It also makes $R_{t}$ uncertain, a crucial ingredient for the gamma discounting argument. I am especially glad that Marty and I were able to get to this common conclusion. It remains to convince countries like the United States to adopt a decreasing discounting system (Arrow et al. 2013). 


\section{Uncertainty}

Uncertainty is ubiquitous in the field of climate change, and we should confess that the economic modelling of the problem has dramatically ignored this crucial aspect in the past. Marty (with some other colleagues such as Bob Pindyck or Christian Traeger) has always been concerned by uncertainty for the estimation of the social cost of carbon. Most integrated assessment models assume no uncertainty at all. When uncertainty is introduced, it is made by assuming that the uncertainty over the next 2 centuries is fully resolved in the next two minutes, so the model can be used under certainty with Monte-Carlo simulations over the distribution of the random parameters of the model (growth, climate sensitivity, marginal abatement cost,...). This method, illustrated for example by the technical report (IAWG 2016) of the Interagency Working Group on the Social Cost of Greenhouse Gases, is an unsatisfactory and unrealistic method to take account of risk.

Let's go back to the basics. The Social Cost of Carbon (SCC) is the present value of the flow of marginal climate damages generated by one ton of $\mathrm{CO} 2$ emitted today. Modern asset pricing theory tells us that the discount rate to be used for this estimation of the SCC should combine a risk-free rate and a risk premium. The Consumption-based Capital Asset Pricing Model (CCAPM) provides an ethically-founded support for this approach. But the simplest version of the CCAPM assumes a bivariate normal distribution for the pair of $\log$ consumption and log benefits. Marty has not been the first to criticize this assumption in his celebrated paper on the asset-return puzzle (Weitzman 2007), but he has certainly provided the most powerful argument against the CCAPM so far in the literature. Applied to climate change and the SCC, his argument became the "dismal theorem" (Weitzman 2009). CCAPM also assumes that relative risk aversion is constant, so that the marginal utility of consumption tends to infinity when consumption tends to zero. This implies that the pricing of assets is extremely sensitive to the fatness of the lower tail of distribution of $\log$ consumption and $\log$ benefits. For example, if the normal distribution is replaced by Student-t, Marty showed that most asset prices become unbounded. Other researchers in finance, such as Marty's Harvard colleague Robert Barro (Barro 2006) or myself (Gollier 2016), have followed a different road at the same time by quantifying the tails of the distribution of consumption growth, yielding finite prices.

The dismal theorem is a negative result which, I think, made Marty more reluctant than ever to value the SCC. The profession always had a bias for positive results. Weitzman's doubts about the "exact" value of the SCC is a badge of honor, but I believe that it greatly played against him when the members of the Nobel Committee had to make their decision.

The last time I met Marty was in May 2019, when we both spent one week in Goteborg under the auspice of an invitation by Thomas Sterner. At this occasion, he made a presentation at a worskshop on the SCC. The title of his presentation was "Why is the economics of climate change so difficult and controversial? (An economist's apology)". His first slide started with the following question "Why is analysis of what to do about climate change an economist's nightmare"? Discounting and uncertainties were his two answers. But here is Marty's final message of the talk: "Economists should stay the course by continuing to pound home the superiority of pricing CO2 emissions. Unanimous economist's voice is powerful over long (or even medium) run". Let's do this! 


\section{References}

Arrow K, Cropper M, Gollier C, Groom B, Heal G, Newell R, Nordhaus W, Pindyck R, Pizer W, Portney P, Sterner T, Tol R, Weitzman M (2013) Determining benefits and costs for future generations. Science 341:349-350

Barro RJ (2006) Rare disasters and asset markets in the twentieth century. Q J Econ 121:823-866

Gollier C (2016) Evaluation of long-dated assets: the role of parameter uncertainty. J Monet Econ 84:66-83

Gollier C, Weitzman ML (2010) How should distant future be discounted when discount rates are uncertain? Econ Lett 107:350-353

IAWG (2016) Interagency Working Group on the Social Cost of Greenhouse Gases: Technical update of the social cost of carbon for regulatory impact analysis under executive order 12866. Technical report, Washington: Executive Office of the President

Weitzman ML (1974) Prices vs quantities. Rev Econ Stud 41:477-491

Weitzman ML (1986) The share economy: conquering stagflation. Harvard University Press, Cambridge MA

Weitzman ML (1998) Why the far-distant future should be discounted at its lowest possible rate? J Environ Econ Manag 36:201-208

Weitzman ML (2001) Gamma discounting. Am Econ Rev 91:260-271

Weitzman ML (2007) Subjective expectations and asset-return puzzle. Am Econ Rev 97:1102-1130

Weitzman ML (2009) On modeling and interpreting the economics of catastrophic climate change. Rev Econ Stat 91(1):1-19

Publisher's Note Springer Nature remains neutral with regard to jurisdictional claims in published maps and institutional affiliations. 